\title{
PEMETAAN LAHAN SAWAH DAN POTENSINYA UNTUK PERLINDUNGAN LAHAN PERTANIAN PANGAN BERKELANJUTAN DI KABUPATEN PASAMAN BARAT, SUMATERA BARAT
}

\section{Mapping Paddy Field and its Potential for Protection of Food Agricultural Land Sustainability in West Pasaman Regency, West Sumatera}

\author{
Muhammad Zulfikar1), Baba Barus $\left.{ }^{2}\right)^{*}$, dan Atang Sutandi2) \\ 1) Staf Dinas Perkebunan dan Hortikultura, Jl. Komplek Pertanian Sukomananti, Kabupaten Pasaman Barat, \\ Provinsi Sumatera Barat \\ 2) Departemen Ilmu Tanah dan Sumberdaya Lahan, Fakultas Pertanian, IPB, Jl. Meranti Kampus IPB Darmaga, \\ Bogor 16680
}

\begin{abstract}
The West Pasaman Regency was formed from division of the Pasaman Regency by Government Decree No.38/2003 dated December 18, 2003. Since 1990, the problems faced by the district is agricultural land conversion to other uses very rapidly, especially conversion of paddy fields into oil palm plantations. The passing of the Law No 41, 2009 on the Protection of Sustainable Food Agricultural Land (PSFAL) is expected to control the pace of agricultural land use change. This regulation still new so that many of its implementations have not been conducted, including the planning and its establishment. The aim of this research were: (1) to analyze public perception of the main factors affecting the sustainability of paddy land, (2) to analyze the projection needs of paddy fields at the district levels, and (3) to select areas for sustainable paddy land area on subdistrict administrative boundary. The results showed that physical factors namely availability of actual and potential land take precedence in determining for sustaining paddy land. The availability of paddy fields in the West Pasaman Region still sufficient to feed themselves for 20 years to come. There is 27,317 ha suitable area could be protected, at Barru District, with existing landuse irrigated paddy field, and 9,871 ha is potential land to be protected, with existing landuse bushes, swamps and swampy areas. The proposed protected land was divided into 3 category, focussed at suplus production area, supported by irrigated, and community acceptance, with area of 18,670 ha, distribute at several sub-districts.
\end{abstract}

Keywords: Paddy field, land Suitability, spatial planning, sustainable food agricultural land

\begin{abstract}
ABSTRAK
Kabupaten Pasaman Barat terbentuk dari pemekaran Kabupaten Pasaman melalui Keputusan Pemerintah No.38 / 2003 tanggal 18 Desember 2003. Sejak tahun 1990 masalah yang dihadapi oleh Kabupaten Pasaman adalah konversi lahan pertanian ke penggunaan lain yang sangat cepat, terutama lahan sawah menjadi perkebunan kelapa sawit. Pengesahan UU No 41 tahun 2009 tentang Perlindungan Lahan Pertanian Pangan Berkelanjutan (PLP2B), diharapkan dapat mengendalikan laju perubahan penggunaan lahan pertanian ke penggunaan lain. Peraturan ini masih baru, sehingga implementasi peraturan ini belum banyak dilakukan, termasuk perencanaan dan penetapan wilayah. Tujuan dari penelitian ini adalah (1) untuk menganalisis persepsi masyarakat terhadap faktor utama yang mempengaruhi penentuan lahan sawah berkelanjutan, (2) untuk menganalisis proyeksi kebutuhan luas sawah di tingkat kabupaten, dan (3) untuk menentukan area sawah berkelanjutan di wilayah penelitian berdasarkan batas wilayah kecamatan. Hasil penelitian menunjukkan bahwa faktor fisik yaitu ketersediaan aktual dan potensial (kesesuaian lahan), diutamakan dalam penentuan sawah yang akan dipertahankan. Ketersediaan lahan sawah eksisting di Kabupaten Pasaman Barat masih cukup untuk mencukupi kebutuhan pangan lokal selama kurang lebih 20 tahun yang akan datang. Terdapat lahan sawah (aktual) seluas 27,317 ha yang cocok untuk dilindungi di Kecamatan Barru, dengan penggunaan lahan eksisting berupa sawah irigasi (budidaya). Selain itu, terdapat lahan potensial untuk dilindungi seluas 9,871 ha, dengan penggunaan lahan eksisting berupa semak-semak, rawa dan rawa lebak. Lahan yang diusulkan di lindungi dibagi menjadi 3 kriteria, yaitu: area yang surplus produksi, adanya irigasi, dan penerimaan oleh masyarakat. Lahan yang mencakup ketiga kriteria tersebut terdapat seluas 18,670 ha yang terdistribusi di beberapa kecamatan.
\end{abstract}

Kata kunci: Lahan sawah, kesesuaian lahan, perencanaan tata ruang, lahan pertanian pangan berkelanjutan 


\section{PENDAHULUAN}

Pangan adalah kebutuhan dasar manusia sehingga pemenuhannya bukan hanya untuk memenuhi hak asasi setiap rakyat Indonesia atau hanya sebagai kewajiban moral saja, tetapi juga merupakan investasi ekonomi maupun sosial dalam rangka pembentukan generasi yang lebih baik pada masa yang akan datang. Indonesia mempunyai keanekaragaman hayati, ekosistem, dan budaya yang sangat tinggi. Kemampuan dan keberadaan biodiversitas pertanian lokal harus dimanfaatkan dan dikembangkan guna meningkatkan dan mempertahankan ketahanan pangan lokal, daerah dan nasional (Kasumbogo, 2010). Apabila setiap masyarakat lokal dapat meningkatkan ketahanan pangannya sesuai dengan kondisinya masing-masing, secara agregat ketahanan pangan nasional yang lebih mantap dan berjangka panjang akan tercapai.

Saat ini permasalahan lahan pertanian di Indonesia adalah alih fungsi lahan pertanian pangan terutama lahan sawah ke penggunaan lain, yang menjadi fenomena hampir di semua wilayah. Dampak yang ditimbulkan dari alih fungsi lahan antara lain adalah ancaman terhadap ketahanan pangan. Bagi sektor pertanian pangan, lahan merupakan faktor produksi pertama dan tidak tergantikan. Berbeda dengan penurunan produksi yang disebabkan oleh serangan hama penyakit, kekeringan, banjir dan lainnya lebih bersifat sementara, penurunan produksi yang diakibatkan oleh alih fungsi lahan bersifat permanen dan sulit untuk diperbaiki (Departemen Pertanian, 2006).

Salah satu upaya pengendalian alih fungsi lahan pertanian pangan dan perlindungan terhadap lahan pertanian pangan produktif dilakukan melalui peraturan perundang-undangan yang diharapkan dapat (1) menjamin tersedianya lahan pertanian yang cukup, (2) mampu mencegah terjadinya alih fungsi lahan pertanian ke penggunaan non pertanian secara tidak terkendali, dan (3) menjamin akses masyarakat petani terhadap lahan pertanian yang tersedia (Departemen Pertanian, 2006).

Kabupaten Pasaman Barat sebelum tahun 1990 merupakan kawasan sentra produksi pangan di Provinsi Sumatera Barat terutama beras dan kedelai. Akan tetapi sejak tahun 1990, permasalahan yang sedang dihadapi adalah adanya alih fungsi lahan sawah ke perkebunan kelapa sawit (Bappeda Kabupaten Pasaman Barat, 2011). Secara sporadis dan kualitatif, kenampakan tanaman kelapa sawit yang berada di hamparan sawah terlihat secara kasat mata di berbagai lokasi, dan dalam beberapa tahun ke depan ada kemungkinan sawah akan berubah menjadi kebun kelapa sawit.

Pengesahan Undang-undang Nomor 41 tahun 2009 tentang Perlindungan Lahan Pertanian Pangan Berkelanjutan (PLP2B) merupakan regulasi yang diharapkan mampu melindungi dan mengendalikan laju konversi lahan pertanian untuk ketahanan pangan berkelanjutan (Sekretaris Kabinet, 2009). Dalam Undangundang PLP2B diatur bahwa Kawasan Pertanian Pangan Berkelanjutan (KP2B) ditetapkan dalam Rencana Tata Ruang Wilayah Kabupaten (RTRWK) dan merupakan bagian dari penetapan rencana tata ruang kawasan pedesaan di wilayah kabupaten, yang didalamnya ada
Lahan Pertanian Pangan Berkelanjutan (LP2B) dan Cadangannya (LCP2B).

Beberapa penelitian penentuan lahan sawah yang dilindungi sudah dilakukan dengan menggunakan analisis berbasis Sistem Informasi Geografis (Christina, 2011; Lanya dan Subadiyasa, 2011) dan menghasilkan berbagai pendekatan spesifik sesuai kondisi tertentu, yang ada kalanya tidak sejalan dengan kriteria yang sudah ditentukan dalam perundangan seperti usulan penetapan di Kabupaten Garut (Barus et al., 2011), dimana daerah sawah yang terancam terkonversi, terdapat di kawasan lindung, atau daerah yang surplus bukan daerah yang produktivitasnya tinggi.

Berdasarkan fakta dan perkembangan tersebut, maka tujuan penelitian ini adalah: 1) menganalisis persepsi publik tentang faktor utama yang menentukan keberlanjutan lahan pangan, 2) menganalisis proyeksi kebutuhan lahan basah di Kabupaten Pasaman Barat, dan 3) memilih lahan pertanian pangan berkelanjutan pada tingkat kecamatan. Selanjutnya, hasil penelitian ini diharapkan dapat dipakai sebagai usulan bagi perencanaan pembangunan pertanian pangan berkelanjutan di Kabupaten Pasaman Barat.

\section{BAHAN DAN METODE}

Penelitian ini dilaksanakan di Kabupaten Pasaman Barat, Provinsi Sumatera Barat. Data primer terdiri dari data hasil survei lapang, data kuesioner dari wawancara ahli, petani dan lainnya, sementara data sekunder terdiri dari tabel dan peta yang diperoleh dari berbagai instansi pemerintah.

Data primer dipakai untuk mengembangkan kepentingan berbagai faktor dalam penyelamatan lahan sawah. Data sekunder yang dipakai antara lain peta penggunaan lahan, peta jaringan irigasi, peta jaringan jalan, peta satuan tanah dan lahan yang diambil dari Bappeda. Penelitian dilakukan dari bulan Mei - Agustus 2012. berikut :

Berbagai analisis yang dilakukan adalah sebagai

\section{a. Analisis dan Pemetaan Kesesuaian Lahan Untuk Tanaman Padi Sawah}

Analisis ini digunakan untuk menilai kesesuaian lahan tanaman padi sawah. Analisis dilakukan dengan mencocokan kualitas lahan dengan kriteria kesesuaian lahan tanaman padi sawah (PPT, 1983 dalam Hardjowigeno dan Widiatmaka, 2007). Kesesuaian lahan disusun menjadi 4 kelas yaitu S1 (sangat sesuai), S2 (sesuai bersyarat), S3 (sesuai marjinal) dan $\mathrm{N}$ (tidak sesuai). Penentuan kesesuaian lahan dilakukan hanya sampai kategori kelas saja. Karakteristik lahan yang dipakai adalah pH, kedalaman tanah, tekstur, elevasi, drainase, dan keadaan banjir serta genangan.

\section{b. Identifikasi Lahan Aktual dan Lahan Potensial Padi Sawah}

Proses ini dilakukan dengan menumpangtindihkan peta kesesuaian lahan sawah dengan peta 
penggunaan lahan. Lahan aktual adalah lahan yang penggunaannya saat ini berupa sawah irigasi dan sawah tadah hujan. Lahan potensial adalah lahan yang penggunaannya saat ini berupa semak belukar, semak belukar rawa, dan rawa.

Kesesuaian untuk lahan sawah aktual dan potensial, dievaluasi berdasarkan kelas kesesuaian lahan kategori kelas sangat sesuai (S1), sesuai (S2), sesuai marjinal (S3), dan tidak sesuai $(\mathrm{N})$ tanpa dirinci faktor pembatas, sedangkan untuk lahan aktual yang potensial dijadikan sawah termasuk tidak banyak, maka evaluasi hanya dilakukan pada kategori ordo $\mathrm{S}$ (sesuai) dan $\mathrm{N}$ (tidak sesuai) saja. Hal ini ditujukan untuk efisiensi evaluasi, karena sawah yang ada, umumnya mengindikasikan kesesuaian lahan yang sudah operasional (mantap). Sawah yang berada pada daerah berlereng dan sudah diteras, berarti dianggap sudah sesuai.

Untuk mencari lahan potensial, maka daerah yang sesuai untuk sawah juga diidentifikasi dari penggunaan lahan yang saat ini berupa rawa, semak belukar dan belukar rawa. Pertimbangannya adalah adanya konversi lahan sawah yang perlu digantikan, atau terjadi degradasi lahan, dan lain-lain, yang akan dijadikan sebagai calon lahan cadangan.

\section{c. Identifikasi Lahan Aktual dan Lahan Potensial berdasarkan Jaringan Infrastruktur}

Idealnya setiap LP2B dan LCP2B mempunyai jaringan infrastruktur pendukung pertanian yaitu berupa jaringan irigasi dan jaringan jalan. Lahan sawah dan potensial sawah, yang mempunyai jaringan irigasi dan jalan akan diberikan prioritas lebih tinggi untuk dilindungi. Metode yang dipakai adalah setiap sawah atau penggunaan lahan potensial dijadikan sawah ditumpang-tindihkan dengan data infrastruktur jalan usaha tani dan irigasi. Jalan usaha tani yang ada adalah jalan utama (penghubung pemukiman dan pertanian), jalan cabang (penghubung petak lahan dengan jalan utama), dan jalan kecil (jalan kecil yang dipakai untuk pemberantasan hama, pemupukan, dan lainnya).

\section{d. Analisis Proyeksi Kebutuhan Lahan Sawah Kabupaten Pasaman Barat}

Analisis proyeksi kebutuhan lahan sawah digunakan untuk mengetahui kebutuhan lahan sawah dalam jangka waktu tertentu serta kontribusinya terhadap kebutuhan beras. Dua skenario yang dipakai, yakni skenario optimis yang mengasumsikan produktivitas naik $1.35 \%$ per tahun dan IP (Indeks Pertanaman) naik 1\% per tahun, konsumsi pangan $106 \mathrm{~kg} \mathrm{kapita}^{-1}$ tahun $^{-1}$, sedangkan skenario pesimis mengasumsikan produktivitas dan IP tetap serta konsumsi pangan sebesar $140 \mathrm{~kg} \mathrm{kapita}^{-1}$ tahun $^{1}$ (Standar PPH Nasional).

Proyeksi jumlah penduduk dilakukan dengan memperhitungkan jumlah penduduk saat ini (Y) dan jumlah penduduk pada tahun dasar (2000) (X) dengan model saturasi sebagai berikut: $\mathrm{Y}=(313,454)+(7,343.46)$ $\mathrm{X}$; sedangkan kebutuhan pangan $(\mathrm{Kp})$ adalah perkalian dari konsumsi beras per kapita (Kb) dengan jumlah penduduk pada tahun tertentu (Yt), dengan persamaan $\mathrm{Kp}=\mathrm{Kb} * \mathrm{Yt} * 62.74 \%$.
Selanjutnya dihitung kebutuhan luas panen (Klp) dengan membagi kebutuhan pagan (Kp) dengan produktivitas (ton $\mathrm{ha}^{-1}$ ), dengan persamaan $\mathrm{Klp}=\mathrm{Kp} / \mathrm{p}$. Dari data ini selanjutnya dihitung Kebutuhan Luas Tanam (KL) yang memperhitungkan Risiko Gagal Panen (Lgp), dengan rumus $\mathrm{Kt}=\mathrm{Klp}+\mathrm{Lgp}$. Risiko Gagal Panen diasumsikan sebesar $1 \%$ luas panen. Setelah itu, dihitung Kebutuhan Lahan Baku Sawah (Ks) yang diturunkan dari pembagian Luas Tanam (Kt) dengan Intensitas Pertanaman (IP), dengan rumus: $\mathrm{Ks}=(\mathrm{Kt} / \mathrm{IP})^{*} 100$. Perhitungan yang dilakukan disini ditujukan untuk menghitung kontribusi kabupaten ke level provinsi.

\section{e. Analisis Proyeksi Kebutuhan Lahan Sawah Tingkat Kecamatan}

Analisis proyeksi ini digunakan untuk mengetahui neraca produksi atau lahan per kecamatan serta kontribusinya bagi ketahanan pangan di Kabupaten Pasaman Barat. Perhitungan proyeksi kebutuhan ini sama dengan perhitungan di tingkat kabupaten, tetapi disini unit perhitungan dilakukan berbasis kecamatan. Dari perhitungan ini akan diketahui kecamatan yang berstatus surplus atau defisit, atau cukup, dalam hal lahan dan juga dalam hal kecukupan pangan.

\section{f. Analisis Persepsi Masyarakat terhadap KP2B}

Persepsi masyarakat, dianalisis dengan metode Analytic Hierarchy Process (AHP) (Saaty, 1993). Faktor utama dalam penetapan KP2B adalah fisik, sosial ekonomi, dan infrastruktur. Input didapatkan dari referensi dan wawancara pakar dan petani padi sawah. Dari penilaian AHP ini akan dihasilkan skor relatif yang mengindikasi kepentingan berbagai faktor utama yang diperlukan untuk melindungi lahan pangan. Semakin tinggi skor relatif faktor tertentu akan mengindikasikan semakin tinggi kepentingan faktor tersebut.

\section{g. Delineasi Lahan untuk Prioritas lahan yang dijadikan LP2B}

Delineasi lahan dilakukan berdasarkan data spasial yang dihasilkan dari kombinasi semua data spasial untuk parameter fisik, infrastruktur dan sosial-ekonomi dengan sistem klasifikasi kriteria jamak pada berbagai faktor. Setiap faktor, yang mempunyai skor tertentu diberikan bobot tertentu, yang diambil dari hasil perhitungan AHP (Analytical Hierarchy Process) (Jankowski, 1995). Tahap ini menghasilkan peta hamparan lahan yang dapat direkomendasikan sebagai LP2B.

\section{HASIL DAN PEMBAHASAN}

\section{Penggunaan Lahan Aktual}

Ada 4 tipe penggunaan lahan yang relatif besar di Kabupaten Pasaman Barat, yaitu perkebunan kelapa sawit (28.46\%), pertanian lahan kering (24.77\%), hutan sekunder (13.95\%) dan pertanian campuran (12.88\%). Sedangkan sawah irigasi dan sawah tadah hujan mencapai $7.70 \%$ dari total luasan penutupan lahan (Tabel 1). Data ini menunjukkan dari sisi luasan dominan kabupaten ini merupakan daerah budidaya, sedangkan daerah berfungsi lindung relatif terbatas, yang ditunjukkan dengan hutan 
primer dan rawa sekunder yang relatif terbatas $(16.64 \%)$. Selain itu daerah sawah yang juga relatif kecil $(7.70 \%)$, menunjukkan keperluan penduduk setempat untuk sawah diduga tidak terlalu besar, dan saat ini kemungkinan konversi lahan sawah dapat terjadi di masa yang akan datang. Dari pengamatan lapang, saat ini sebagian sawah sudah disisipi dengan tanaman kelapa sawit. Jika sawah ini terkonversi, maka ketahanan atau kemandirian pangan perlu diwaspadai.
Secara keruangan (Gambar 1), daerah berhutan terletak di bagian utara, sedangkan daerah sawah, pertanian campuran dan lahan kering menyebar di semua wilayah. Kenampakan lahan terbuka yang dekat dengan daerah berhutan dianggap dapat mengancam potensi ketersediaan air yang diperlukan untuk menjaga sawah yang ada, atau untuk keperluan pengembangan sawah yang baru jika diperlukan.

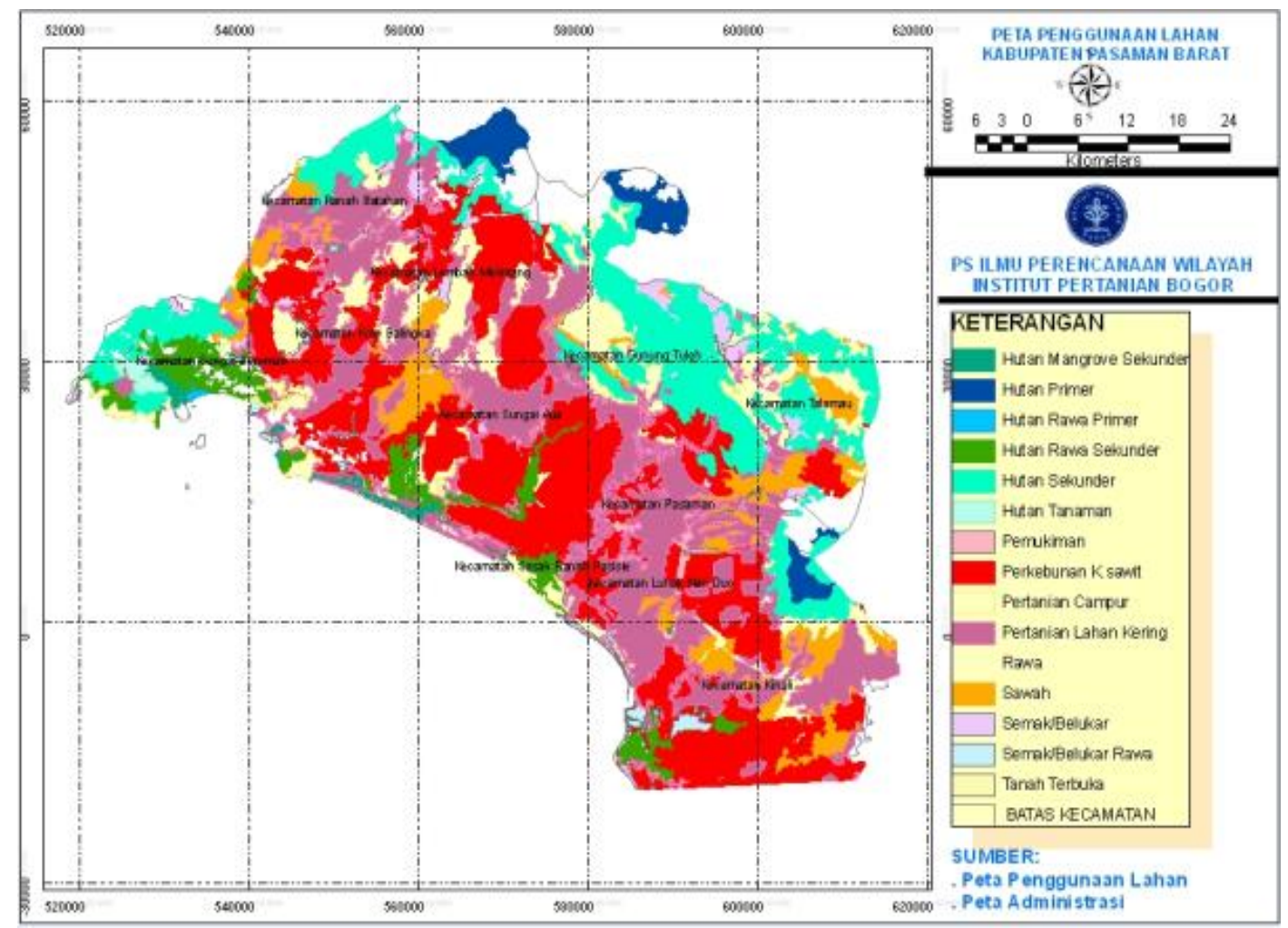

Gambar 1. Peta penggunaan lahan tahun 2012 Kabupaten Pasaman Barat

Tabel 1. Tipe penggunaan lahan 2012, luas dan persentasenya di Pasaman Barat

\begin{tabular}{|c|c|c|c|}
\hline No. & $\begin{array}{l}\text { Penutupan / Penggunaaan } \\
\text { Lahan }\end{array}$ & Luas (ha) & Persentase $(\%)$ \\
\hline 1 & Hutan Primer & 9,494 & 2.69 \\
\hline 2 & Hutan Mangrove Skunder & 1,530 & 0.43 \\
\hline 3 & Hutan Rawa Primer & 187 & 0.05 \\
\hline 4 & Hutan Rawa Skunder & 12,581 & 3.56 \\
\hline 5 & Hutan Skunder & 49,332 & 13.95 \\
\hline 6 & Hutan Tanaman & 1,180 & 0.33 \\
\hline 7 & Pemukiman & 3,699 & 1.05 \\
\hline 8 & Pertanian Campuran & 45,557 & 12.88 \\
\hline 9 & Perkebunan Kelapa Sawit & 100,642 & 28.46 \\
\hline 10 & Pertanian Lahan Kering & 87,595 & 24.77 \\
\hline 11 & Rawa & 106 & 0.03 \\
\hline 12 & Sawah Irigasi & 20,550 & 5.81 \\
\hline 13 & Sawah Tadah Hujan & 6,681 & 1.89 \\
\hline 14 & Semak Belukar & 10,299 & 2.91 \\
\hline 15 & Semak belukar rawa & 2,826 & 0.80 \\
\hline \multirow[t]{2}{*}{16} & Tanah Terbuka & 1,556 & 0.38 \\
\hline & Jumlah & 353,588 & 100,00 \\
\hline
\end{tabular}

\section{Kesesuaian Lahan untuk Tanaman Padi Sawah}

Berdasarkan evaluasi data kesesuaian penggunaan lahan untuk padi sawah maka sawah irigasi tergolong kelas S1, dan sebagian sawah tadah hujan tergolong kelas
S2 atau S3. Jika diperlukan perluasan sawah maka sebagian besar wilayah Pasaman Barat adalah sesuai untuk dikembangkan sebagai lahan sawah. Wilayah yang saat ini sebagai daerah hutan primer, hutan sekunder, lahan kering, dan lainnya mempunyai lokasi yang secara fisik sudah sesuai untuk dijadikan sawah (Tabel 2).

Dengan adanya ancaman konversi lahan sawah ke bentuk lain, maka untuk penambahannya atau kompensasinya juga dapat dilakukan. Berdasarkan potensi kemudahan dikonversinya penggunaan lahan ke sawah dan mempunyai kesesuaian lahan sawah, maka daerah semak belukar dan rawa masih banyak yang dapat dimanfaatkan sebagai daerah potensial lahan sawah.

\section{Identifikasi Lahan Aktual dan Potensial untuk Pengembangan Padi Sawah}

\section{Lahan Aktual sebagai Usulan untuk LP2B}

Hasil analisis menunjukkan, bahwa sawah irigasi berkelas kesesuaian lahan S1 seluas 20,547 ha dan S2 seluas 37 ha (penghambat lereng tetapi sudah di teras). Sawah tadah hujan berkelas kesesuaian lahan S1 seluas 3,803 ha, S2 seluas 4,144 ha (penghambat curah hujan) dan S3 seluas 76 ha (penghambat tekstur tanah) dari total 
luasan sawah aktual yang tersebar di 9 kecamatan yaitu:

Kinali, Luhak ND, Talamau, Pasaman, G. Tuleh, L. Melintang, K. Balingka, R. Batahan dan S. Beremas.

Lahan aktual terluas terletak di Kecamatan Kinali

seluas 8,002 ha atau 29\% dari total luas lahan aktual, sedangkan luas lahan aktual terkecil berada di Kecamatan K. Balingka 273 ha atau $1 \%$ dari total luas lahan aktual. Selengkapnya data tersebut disajikan pada Tabel 3 dan Gambar 4.

Tabel 2. Kesesuaian lahan untuk sawah berdasarkan penggunaan lahan

\begin{tabular}{|c|c|c|c|c|c|c|c|}
\hline \multirow{2}{*}{ No. } & \multirow{2}{*}{ Penutupan / Penggunaaan Lahan } & \multicolumn{4}{|c|}{ Kelas Kesesuaian Lahan } & \multirow{2}{*}{ Luas (ha) } & \multirow{2}{*}{$(\%)$} \\
\hline & & \multicolumn{3}{|c|}{ Sesuai } & $\mathrm{N}$ & & \\
\hline 1 & Hutan Primer & \multicolumn{3}{|c|}{6,910} & 2,584 & 9,494 & 2.69 \\
\hline 2 & Hutan Mangrove Sekunder & \multicolumn{3}{|c|}{1,281} & 249 & 1,530 & 0.43 \\
\hline 3 & Hutan Rawa Primer & \multicolumn{3}{|c|}{187} & 0 & 187 & 0.05 \\
\hline 4 & Hutan Rawa Sekunder & \multicolumn{3}{|c|}{12,581} & 0 & 12,581 & 3.56 \\
\hline 5 & Hutan Skunder & \multicolumn{3}{|c|}{46,993} & 2,339 & 49,332 & 13.95 \\
\hline 6 & Hutan Tanaman & \multicolumn{3}{|c|}{1,180} & 0 & 1,180 & 0.33 \\
\hline 7 & Pemukiman & \multicolumn{3}{|c|}{3,672} & 27 & 3,699 & 1.05 \\
\hline 8 & Pertanian Campuran & \multicolumn{3}{|c|}{43,646} & 1,910 & 45,557 & 12.88 \\
\hline 9 & Perkebunan Kelapa Sawit & \multicolumn{3}{|c|}{100,642} & 0 & 100,642 & 28.46 \\
\hline 10 & Pertanian Lahan Kering & \multicolumn{3}{|c|}{87,127} & 468 & 87,595 & 24.77 \\
\hline \multirow[t]{2}{*}{16} & Tanah Terbuka & \multicolumn{3}{|c|}{1,329} & 0 & 1,329 & 0.38 \\
\hline & & S1 & $\mathrm{S} 2$ & S3 & & & \\
\hline 11 & Rawa & 106 & 0 & 0 & 0 & 106 & 0.03 \\
\hline 12 & Sawah Irigasi & 15,811 & 0 & 4,732 & 7 & 20,550 & 5.82 \\
\hline 13 & Sawah Tadah Hujan & 3,925 & 0 & 0 & 2,756 & 6,681 & 1.88 \\
\hline 14 & Semak Belukar & 1,093 & 287 & 2,038 & 6,881 & 10,299 & 2.91 \\
\hline 15 & Semak belukar rawa & 986 & 204 & 85 & 281 & 1,556 & 0.80 \\
\hline \multicolumn{2}{|r|}{ Jumlah } & & & & & 353,581 & 100,00 \\
\hline
\end{tabular}

Tabel 3. Luas lahan sawah irigasi dan sawah tadah hujan di kecamatan

\begin{tabular}{|c|c|c|c|c|c|c|c|c|c|c|c|c|c|}
\hline \multirow{3}{*}{ No } & \multirow{3}{*}{ Kecamatan } & \multicolumn{10}{|c|}{ Sawah (ha) } & \multirow{3}{*}{$\begin{array}{r}\text { Total } \\
\text { (ha) } \\
(\mathrm{c}+\mathrm{d})\end{array}$} & \multirow{3}{*}{$\%$} \\
\hline & & \multicolumn{4}{|c|}{ Irigasi } & \multirow{2}{*}{$\begin{array}{r}\text { Jumlah } \\
\text { (ha) }\end{array}$} & \multicolumn{4}{|c|}{ Tadah Hujan } & \multirow{2}{*}{$\begin{array}{r}\text { Jumlah } \\
\text { (ha) }\end{array}$} & & \\
\hline & & $\mathrm{S} 1$ & $\mathrm{~S} 2$ & $\mathrm{~S} 3$ & $\mathrm{~N}$ & & S1 & S2 & S3 & $\mathrm{N}$ & & & \\
\hline $\mathrm{a}$ & $\mathrm{b}$ & \multicolumn{4}{|c|}{$\mathrm{c}$} & \multicolumn{5}{|c|}{$\mathrm{d}$} & & $\mathrm{e}$ & $\mathrm{f}$ \\
\hline 1 & G.Tuleh & 279 & 0 & 462 & 0 & 741 & 0 & 0 & 0 & 37 & 0 & 778 & 3 \\
\hline 2 & Kinali & 7,538 & 0 & 464 & 0 & 8,002 & 0 & 0 & 0 & 0 & 0 & 8,002 & 29 \\
\hline 3 & Pasaman & 936 & 0 & 3,806 & 0 & 4,742 & 0 & 0 & 0 & 0 & 0 & 4,742 & 17 \\
\hline 4 & Talamau & 0 & 0 & 0 & 7 & 7 & 0 & 0 & 0 & 2,719 & 2,719 & 2,726 & 10 \\
\hline 5 & Luhak ND & 858 & 0 & 0 & 0 & 858 & 0 & 0 & 0 & 0 & 0 & 858 & 3 \\
\hline 6 & Sasak RP & 0 & 0 & 0 & 0 & 0 & 0 & 0 & 0 & 0 & 0 & 0 & 0 \\
\hline 7 & S.Aur & 0 & 0 & 0 & 0 & 0 & 0 & 0 & 0 & 0 & 0 & 0 & 0 \\
\hline 8 & L. Melintang & 5,927 & 0 & 0 & 0 & 5,927 & 0 & 0 & 0 & 0 & 0 & 5,927 & 22 \\
\hline 9 & K.Balingka & 273 & 0 & 0 & 0 & 273 & 0 & 0 & 0 & 0 & 0 & 273 & 1 \\
\hline 10 & R.Batahan & 0 & 0 & 0 & 0 & 0 & 2,608 & 0 & 0 & 0 & 2,608 & 2,608 & 10 \\
\hline \multirow[t]{2}{*}{11} & S. Beremas & 0 & 0 & 0 & 0 & 0 & 1,317 & 0 & 0 & 0 & 1,317 & 1,317 & 5 \\
\hline & & 20,547 & & 4,732 & & 20,550 & 3,925 & & & 2,756 & 6,684 & 27,231 & 100 \\
\hline
\end{tabular}

\section{Lahan Potensial sebagai Usulan untuk LCP2B}

Kondisi penutupan/penggunaan lahan yang dipilih sesuai dan berpotensi untuk lahan sawah adalah lahan yang berupa rawa, semak belukar dan semak belukar rawa, dengan pertimbangan jika dimasa yang akan datang lahan pertanian pangan mengalami degradasi akibat alih fungsi lahan atau penyebab lainnya.
Hasil análisis menunjukkan, bahwa ketersediaan lahan potensial di Kabupaten Pasaman Barat masih besar yakni 10,975 ha. Potensi lahan potensial terbesar berada di Kecamatan Talamau yakni 3,047 ha atau 28\% dari total luasan lahan potensial. Luas lahan potensial terkecil berada di Kecamatan Luhak ND yakni 43 ha atau $0.4 \%$ dari total luasan lahan potensial (Tabel 4 dan Gambar 2).

Tabel 4. Lahan potensial sawah (rawa,semak belukar, semak belukar rawa) per kecamatan

\begin{tabular}{|c|c|c|c|c|c|c|c|c|c|c|c|c|c|}
\hline \multirow{2}{*}{ No } & \multirow{2}{*}{ Kecamatan } & \multirow{2}{*}{$\frac{\text { Rawa }}{\mathrm{S} 1}$} & \multicolumn{3}{|c|}{ Semak Belukar } & \multirow{2}{*}{$\begin{array}{l}\text { Total } \\
\text { (ha) }\end{array}$} & \multicolumn{3}{|c|}{$\begin{array}{c}\text { Semak Belukar } \\
\text { Rawa } \\
\end{array}$} & \multirow{2}{*}{$\begin{array}{c}\text { Sub } \\
\text { Total } \\
\text { (ha) }\end{array}$} & \multirow{2}{*}{$\begin{array}{l}\text { Luas } \\
\text { S (ha) }\end{array}$} & \multirow{2}{*}{$\begin{array}{l}\text { Luas Kec Total } \\
\quad(\mathrm{S} \text { dan } \mathrm{N})\end{array}$} & \multirow[t]{2}{*}{$\begin{array}{l}\% \text { di } \\
\text { Kec }\end{array}$} \\
\hline & & & $\mathrm{S} 1$ & $\mathrm{~S} 2$ & $\mathrm{~S} 3$ & & $\mathrm{~S} 1$ & $\mathrm{~S} 2$ & $\mathrm{~S} 3$ & & & & \\
\hline 1 & G.Tuleh & 0 & 75 & 0 & 325 & 400 & 0 & 0 & 0 & 0 & 400 & 2,333 & 17.1 \\
\hline 2 & Kinali & 0 & 229 & 0 & 0 & 229 & 87 & 80 & 85 & 252 & 481 & 8,537 & 5.6 \\
\hline 3 & Pasaman & 106 & 111 & 0 & 24 & 251 & 0 & 0 & 0 & 0 & 251 & 5,122 & 4.9 \\
\hline 4 & Talamau & 0 & 0 & 0 & 0 & 0 & 0 & 0 & 0 & 0 & 0 & 5,631 & - \\
\hline 5 & Luhak ND & 0 & 0 & 0 & 0 & 0 & 0 & 43 & 0 & 43 & 43 & 901 & 4.8 \\
\hline 6 & Sasak RP & 0 & 0 & 0 & 0 & 0 & 88 & 0 & & 88 & 88 & 495 & 17.8 \\
\hline 7 & S.Aur & 0 & 242 & 0 & 0 & 242 & 108 & 0 & 0 & 108 & 350 & 471 & 74.3 \\
\hline 8 & L. Melintang & 0 & 158 & 0 & 0 & 158 & 0 & 81 & 0 & 81 & 239 & 7,924 & 3.0 \\
\hline 9 & K.Balingka & 0 & 0 & 0 & 251 & 251 & 130 & 0 & 0 & 130 & 381 & 810 & 47.0 \\
\hline 10 & R.Batahan & 0 & 0 & 0 & 212 & 212 & 104 & 0 & 0 & 104 & 316 & 3,993 & 7.9 \\
\hline \multirow[t]{2}{*}{11} & S. Beremas & 0 & 278 & 287 & 624 & 1,189 & 469 & 0 & 0 & 469 & 1,658 & 2,975 & 55.7 \\
\hline & Jumlah & 106 & 1,093 & 287 & 1,436 & 2,932 & 986 & 204 & 85 & 1,436 & 4,207 & 39,192 & 10.7 \\
\hline
\end{tabular}




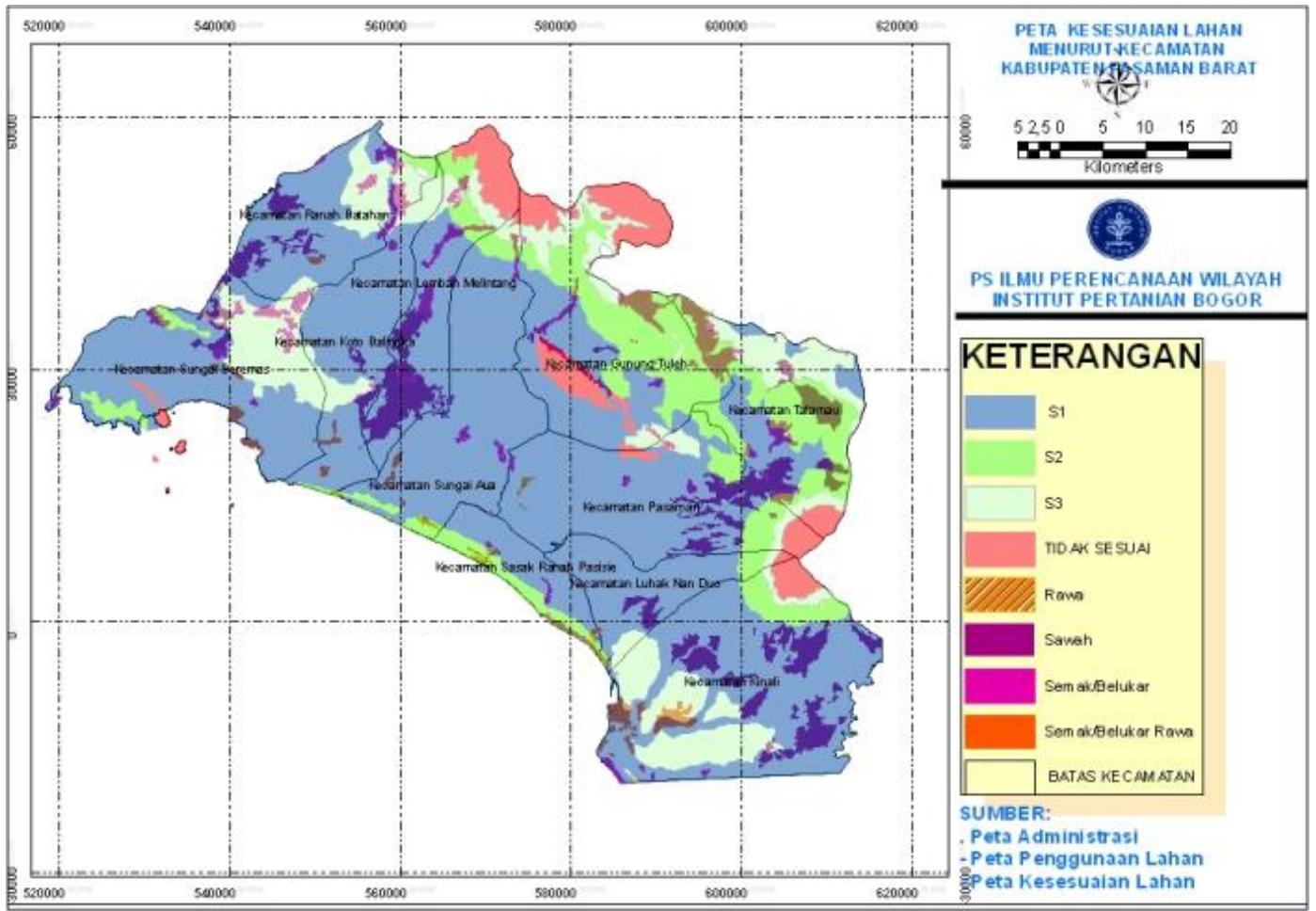

Gambar 2. Peta lahan aktual dan potensial untuk LP2B

\section{Identifikasi Lahan Pertanian Pangan berdasarkan Infrastruktur}

Tahapan ini menghasilkan peta lahan aktual dan potensial yang memiliki jaringan jalan dan irigasi. Dengan pendekatan ini maka diketahui keberadaan sawah aktual dan cadangannya. Gambar 4 menunjukkan sebagian sawah mempunyai jaringan irigasi dan jalan tani. Data infrastruktur ini juga akan dipakai untuk penentuan sawah yang dilindungi.

\section{Analisis Proyeksi Kebutuhan Lahan Sawah}

Dari 2 (dua) skenario yang dibuat, hasilnya menunjukkan bahwa pada skenario optimis terjadi penurunan kebutuhan lahan sawah setiap tahunnya, sebaliknya skenario pesimis terjadi peningkatan kebutuhan lahan sawah tiap tahunnya. Uraian lengkap disajikan di bawah ini.

\section{Skenario Optimis}

Penurunan kebutuhan lahan sawah untuk skenario optimis terjadi karena perluasan areal tanam dan kenaikan produktivitas. Hal ini dilakukan dengan perbaikan prasarana pendukung seperti irigasi dan kemajuan IPTEK. Perhitungan ini mengasumsikan tidak terjadi degradasi lahan dan konversi lahan. Permasalahan lain yang dihadapi petani saat ini adalah banyaknya jaringan irigasi yang rusak. Berdasarkan skenario ini, hingga tahun 2031 proyeksi intensitas pertanaman di kabupaten ini masih belum mampu mencapai IP 2 kali tanam per tahun, tetapi produktivitas sudah mencapai 6,626 ton $\mathrm{ha}^{-1}$.

\section{Skenario Pesimis}

Dalam skenario ini kebutuhan lahan sawah setiap tahunnya cenderung naik, baik untuk memenuhi kebutuhan pangan di Kabupaten Pasaman Barat maupun berkontribusi terhadap Provinsi Sumatera Barat (Gambar $3)$.

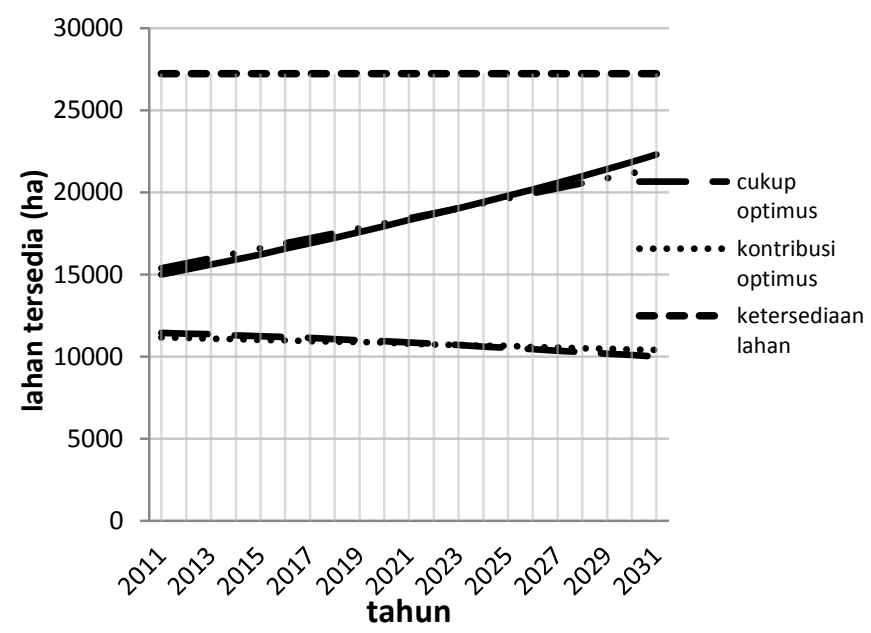

Gambar 3. Proyeksi kebutuhan lahan sawah Kabupaten Pasaman Barat

Tabel 5. Proyeksi kebutuhan lahan sawah Kabupaten Pasaman Barat

\begin{tabular}{|c|c|c|c|c|c|}
\hline Tahun & $\begin{array}{l}\text { Cukup } \\
\text { Optimis }\end{array}$ & $\begin{array}{c}\text { Kontribusi } \\
\text { Optimis }\end{array}$ & $\begin{array}{l}\text { Lahan } \\
\text { tersedia }\end{array}$ & $\begin{array}{l}\text { Cukup } \\
\text { Pesimis }\end{array}$ & $\begin{array}{c}\text { Kontribusi } \\
\text { Pesimis }\end{array}$ \\
\hline & \multicolumn{5}{|c|}{ 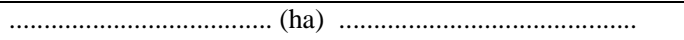 } \\
\hline 2012 & 11,417 & 11,149 & 27,317 & 15,695 & 15,314 \\
\hline 2016 & 11,203 & 10,992 & 27,317 & 16,910 & 16,576 \\
\hline 2021 & 10,863 & 10,794 & 27,317 & 18,428 & 18,301 \\
\hline 2026 & 10,462 & 10,599 & 27,317 & 19,947 & 20,206 \\
\hline 2031 & 10,017 & 10,409 & 27,317 & 21,465 & 22,309 \\
\hline
\end{tabular}

Dari hasil analisis, diketahui pada tahun 2012, kabupaten ini memerlukan mínimum lahan sawah 11,149 ha, dan maksimum lahan 15,695 ha, secara singkat 
disajikan pada Tabel 5. Pilihan ini digunakan untuk mempermudah pengambilan keputusan dan kebijakan yang akan diambil selanjutnya oleh pemerintah daerah kabupaten dalam memenuhi kebutuhan pangan daerahnya.

\section{Analisis Proyeksi Kebutuhan Lahan Sawah Tingkat Kecamatan}

Analisis proyeksi kebutuhan lahan sawah tingkat kecamatan di Kabupaten Pasaman Barat, disajikan pada Tabel 6. Dari hasil analisis, diketahui bahwa pada tahun 2012, kecamatan yang mengalami surplus produksi beras adalah S. Beremas, R. Batahan, L. Melintang, Talamau, Pasaman dan Kinali. Sedangkan kecamatan yang mengalami defisit lahan adalah K. Balingka, S. Aur, G. Tuleh, Luhak ND dan Sasak RP.

\section{Analisis Persepsi Masyarakat terhadap KP2B}

Hasil perbandingan berpasangan penentuan faktor/kriteria yang mempengaruhi penetapan KP2B dengan metode AHP disajikan pada Tabel 7.

Tabel 6. Proyeksi kebutuhan lahan sawah kecamatan

\begin{tabular}{|c|c|c|c|c|c|c|c|}
\hline Kecamatan & Tahun & $\begin{array}{c}\text { Cukup } \\
\text { Optimis }\end{array}$ & $\begin{array}{c}\text { Kontribusi } \\
\text { Optimis }\end{array}$ & $\begin{array}{c}\text { Lahan } \\
\text { tersedia }\end{array}$ & $\begin{array}{l}\text { Cukup } \\
\text { Pesimis }\end{array}$ & $\begin{array}{c}\text { Kontribusi } \\
\text { Pesimis }\end{array}$ & Keterangan \\
\hline & & & & .....(ha).... & ................... & $\ldots$ & \\
\hline \multirow[t]{2}{*}{ S. Beremas } & 2012 & 752 & 1,252 & 1,317 & 1,012 & 1,282 & Surplus \\
\hline & 2031 & 688 & 1,141 & 1,317 & 1,391 & 1,753 & Defisit \\
\hline \multirow[t]{2}{*}{ R. Batahan } & 2012 & 823 & 1,252 & 2,697 & 1,108 & 1,282 & Surplus \\
\hline & 2031 & 722 & 1,114 & 2,697 & 1,515 & 1,753 & Surplus \\
\hline \multirow[t]{2}{*}{ K. Balingka } & 2012 & 893 & 1,252 & 273 & 1,203 & 1,282 & Defisit \\
\hline & 2031 & 784 & 1,099 & 273 & 1,645 & 1,753 & Defisit \\
\hline \multirow[t]{2}{*}{ S. Aur } & 2012 & 1,058 & 1,252 & 0 & 1,425 & 1,282 & Defisit \\
\hline & 2031 & 928 & 1,099 & 0 & 1,948 & 1,753 & Defisit \\
\hline \multirow[t]{2}{*}{ L. Melintang } & 2012 & 1,438 & 1,252 & 5,927 & 1,936 & 1,282 & Surplus \\
\hline & 2031 & 1,262 & 1,099 & 5,927 & 2,648 & 1,753 & Surplus \\
\hline \multirow[t]{2}{*}{ G.Tuleh } & 2012 & 697 & 1,252 & 777 & 938 & 1,282 & Defisit \\
\hline & 2031 & 611 & 1,099 & 777 & 1,283 & 1,753 & Defisit \\
\hline \multirow[t]{2}{*}{ Talamau } & 2012 & 887 & 1,252 & 2,726 & 1,195 & 1,282 & Surplus \\
\hline & 2031 & 779 & 1,099 & 2,726 & 1,634 & 1,753 & Surplus \\
\hline \multirow[t]{2}{*}{ Pasaman } & 2012 & 2,156 & 1,252 & 4,742 & 2,903 & 1,282 & Surplus \\
\hline & 2031 & 1,892 & 1,099 & 4,742 & 3,971 & 1,753 & Surplus \\
\hline \multirow[t]{2}{*}{ Luhak ND } & 2012 & 1,283 & 1,252 & 858 & 1,728 & 1,282 & Defisit \\
\hline & 2031 & 1,126 & 1,099 & 858 & 2,363 & 1,753 & Defisit \\
\hline \multirow[t]{2}{*}{ Sasak RP } & 2012 & 454 & 1,252 & 0 & 611 & 1,282 & Defisit \\
\hline & 2031 & 398 & 1,099 & 0 & 836 & 1,753 & Defisit \\
\hline \multirow[t]{2}{*}{ Kinali } & 2012 & 2,085 & 1,252 & 8,001 & 2,808 & 1,282 & Surplus \\
\hline & 2031 & 1,829 & 1,099 & 8,001 & 3,840 & 1,753 & Surplus \\
\hline
\end{tabular}

Tabel 7. Bobot dan skor untuk setiap faktor dan kriteria hasil perbandingan berpasangan.

\begin{tabular}{|c|c|c|c|c|}
\hline Faktor & Bobot & Kriteria & Skor & $\begin{array}{c}\text { Nilai Akhir } \\
\text { (Bobot x Skor) }\end{array}$ \\
\hline \multirow[t]{2}{*}{ Fisik } & 0.382 & Ketersediaan Lahan Aktual dan Potensial & 0.577 & 0.220 \\
\hline & & Kesesuaian Fungsi dengan RTRW & 0.423 & 0.162 \\
\hline \multirow{2}{*}{ Sosek } & & Indeks Pertanaman & 0.318 & 0.099 \\
\hline & & Subsidi dan Pemasaran & 0.253 & 0.079 \\
\hline \multirow[t]{3}{*}{ Infrastruktur } & 0.307 & Ketersediaan Jaringan Irigasi & 0.421 & 0.129 \\
\hline & & Ketersediaan Jaringan Jalan & 0.359 & 0.110 \\
\hline & & Jarak dari IKK & 0.220 & 0.068 \\
\hline
\end{tabular}

Tabel 8. Prioritas lahan yang dilindungi berdasarkan kombinasi nilai faktor

\begin{tabular}{|c|c|c|c|c|c|c|c|c|c|c|c|}
\hline \multirow[b]{2}{*}{ Kecamatan } & \multirow[b]{2}{*}{$\begin{array}{l}\text { LA } \\
\text { (ha) }\end{array}$} & \multirow[b]{2}{*}{$\begin{array}{l}\text { LP } \\
\text { (ha) }\end{array}$} & \multicolumn{2}{|c|}{ Fisik } & \multicolumn{2}{|c|}{ Sosial Ekonomi } & \multicolumn{2}{|c|}{ Infrastruktur } & \multirow[b]{2}{*}{$\begin{array}{l}\text { Jumlah } \\
\text { Nilai }\end{array}$} & \multirow[b]{2}{*}{ Proyeksi } & \multirow[b]{2}{*}{$\begin{array}{l}\text { Prio- } \\
\text { ritas }\end{array}$} \\
\hline & & & LALP & RTRW & Prod. & IP & Irigasi & $\begin{array}{c}\text { Jar } \\
\text { Jalan }\end{array}$ & & & \\
\hline S. Beremas & 1,317 & 1,658 & 0.22 & 0.162 & 0.133 & 0.099 & 0 & 0.11 & 0.724 & Defisit & 3 \\
\hline K. Balingka & 273 & 536 & 0.22 & 0.162 & 0.133 & 0.099 & 0.129 & 0.11 & 0.853 & Defisit & 2 \\
\hline S. Aur & 0 & 550 & 0.22 & 0.162 & 0 & 0 & 0 & 0 & 0.382 & Defisit & 4 \\
\hline L. Melintang & 5,927 & 1,916 & 0.22 & 0.162 & 0.133 & 0.099 & 0.129 & 0.11 & 0.853 & Surplus & 1 \\
\hline G.Tuleh & 777 & 349 & 0.22 & 0.162 & 0.133 & 0.099 & 0.129 & 0.11 & 0.853 & Defisit & 2 \\
\hline Talamau & 2,726 & 3,047 & 0.22 & 0.162 & 0.133 & 0.099 & 0 & 0.11 & 0.724 & Surplus & 3 \\
\hline Pasaman & 4,742 & 380 & 0.22 & 0.162 & 0.133 & 0.099 & 0.129 & 0.11 & 0.853 & Surplus & 1 \\
\hline Luhak ND & 858 & 43 & 0.22 & 0.162 & 0.133 & 0.099 & 0.129 & 0.11 & 0.853 & Defisit & 2 \\
\hline Sasak RP & 0 & 554 & 0.22 & 0.162 & 0 & 0 & 0 & 0 & 0.382 & Defisit & 4 \\
\hline Kinali & 8,001 & 560 & 0.22 & 0.162 & 0.133 & 0.099 & 0.129 & 0.11 & 0.853 & Surplus & 1 \\
\hline
\end{tabular}


Prioritas berturut-turut dari nilai tertinggi sampai terendah adalah faktor fisik, sosial ekonomi dan infrastruktur. Para pakar yang terdiri dari birokrat, akademisi dan LSM menilai bahwa faktor ketersediaan dan kesesuaian lahan lebih diutamakan dalam penetapan KP2B dibandingkan dengan faktor irigasi dan jalan serta produktivitas, indeks pertanaman, dan pemasaran. Pemilihan penetapan KP2B harus memperhatikan ketersediaan lahan aktual dan potensial saat ini serta ketersediaannya di kawasan budidaya sesuai dengan RTRW Kabupaten Pasaman Barat 2011-2031.

\section{Delineasi Lahan Berdasarkan Hasil AHP dan Proyeksi Kebutuhan Lahan Sawah}

Lahan aktual dan potensial yang tersedia di Kabupaten Pasaman Barat sebesar 38,291 ha. Setelah penapisan mengalami pengurangan seluas 1,104 ha, menjadi seluas 37,187 ha. Hal ini disebabkan lahan potensial yang berada di Kecamatan Sasak Ranah Pasisie seluas 544 ha dan S. Aur seluas 550 ha, dikeluarkan. Alasannya adalah a) kedua kecamatan tersebut tidak memiliki lahan sawah aktual, dan b) lahan potensial sebagian besar telah diusahakan untuk kebun kelapa sawit (Survei lapang, 2012; Sawit Watch, 2010).

Delineasi berdasarkan prioritas ini, memunculkan 3 usulan kategori Lahan Pertanian Pangan Berkelanjutan (LP2B). LP2B kategori 1 di Kecamatan Pasaman, Kinali dan L. Melintang 21,525 ha. LP2B kategori 2 di Kecamatan K. Balingka, Luhak ND dan G. Tuleh 2,836 ha. LP2B kategori 3 di KecamatanTalamau, R. Batahan dan S. Beremas 12,829 ha, dan total LP2B adalah total seluas 37,187 ha. Hasil analisis secara spasial disajikan di Gambar 4.

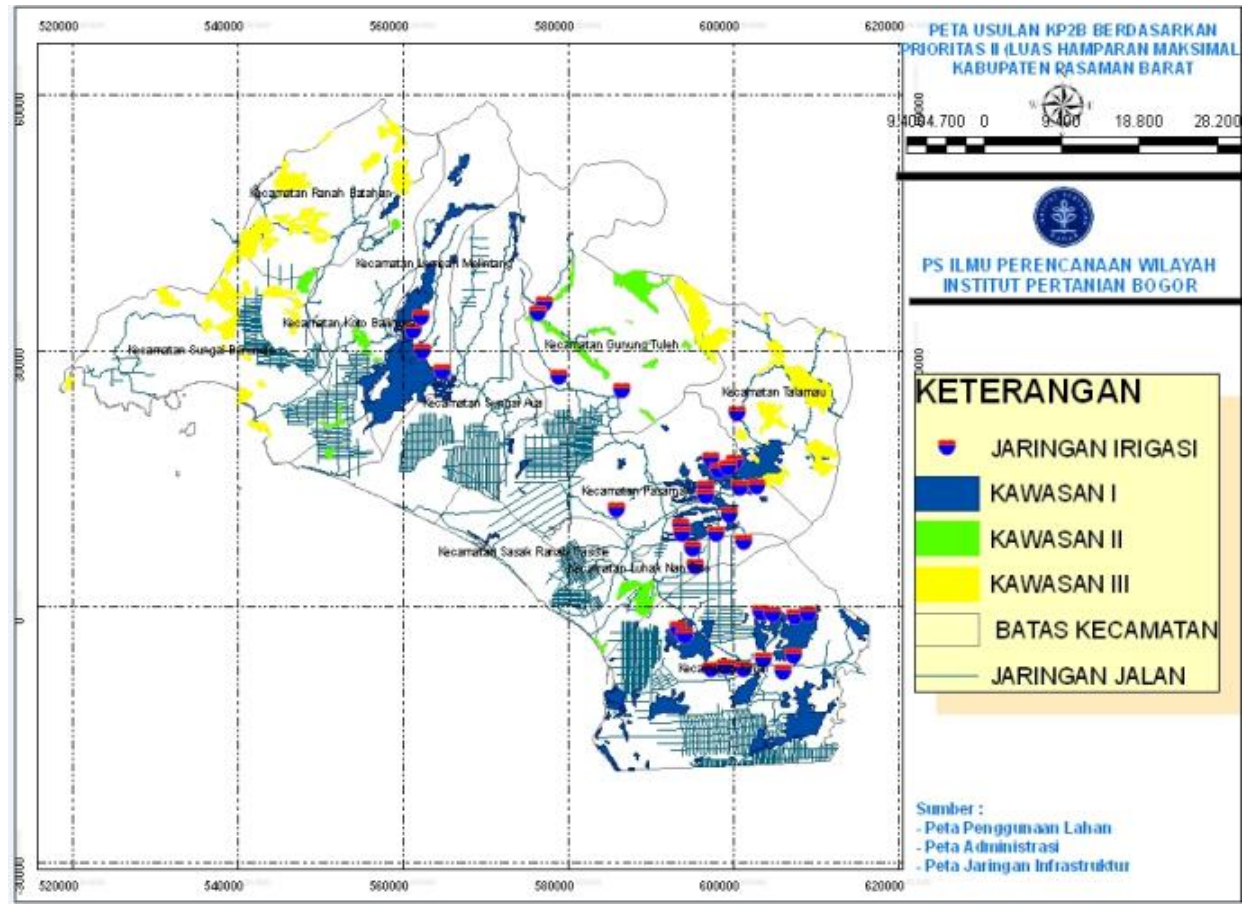

Gambar 4. Peta usulan LP2B berdasarkan nilai AHP dan proyeksi kebutuhan

\section{SIMPULAN}

Berdasarkan hasil penelitian, maka disusun beberapa kesimpulan sebagai berikut :

1. Kabupaten Pasaman Barat mempunyai areal dengan penggunaan lahan sawah aktual yaitu sawah irigasi seluas 20,584 ha dan sawah tadah hujan seluas 6,733 ha. Penutupan/penggunaan lahan berupa rawa seluas 106 ha, semak/belukar seluas 9,146 ha dan semak belukar rawa seluas 1,722 ha dapat dijadikan sebagai lahan potensial untuk tanaman padi sawah.

2. Kelas kesesuaian lahan untuk penggunaan lahan pada sawah irigasi yaitu S1 seluas 20,547 ha dan S2 seluas 37 ha. Sawah tadah hujan berkelas S1 seluas 4,014 ha, S2 seluas 2,643 ha dan S3 seluas 76 ha. Rawa berkelas S1 seluas 106 ha. Semak belukar berkelas S1 seluas 4,954 ha, S2 seluas 3,015 ha, S3 seluas 1,117 ha serta semak belukar berkelas $\mathrm{S} 1$ seluas 1,267 ha,
S2 seluas 370 ha dan S3 seluas 85 ha. Hambatan kesesuaian untuk kelas S2 terdiri dari lereng dan curah hujan, sedangkan hambatan untuk kelas S3 adalah tekstur tanah.

3. Berdasarkan pertimbangan hasil analisis AHP dan proyeksi kebutuhan lahan sawah, maka terdapat 3 kategori lahan yang diusulkan sebagai LP2B dengan luas berbeda. Kategori pertama diprioritaskan untuk dilindungi seluas 18,770 ha yang menyebar di Kecamatan L. Melintang, Pasaman dan Kinali.

\section{SARAN}

Pemerintah Kabupaten Pasaman Barat dapat memanfaatkan hasil riset ini untuk Revisi RTRW Kabupaten Pasaman Barat, sehingga keberadaan LP2B yang representatif dapat diterima di tengah-tengah masyarakat secara formal. 


\section{DAFTAR PUSTAKA}

Bappeda. 2011. Pasaman Barat Dalam Angka 2011. Badan Perencanaan Pembangunan Daerah, Kabupaten Pasaman Barat.

Barus, B., D.R. Panuju, L.S. Iman, B.H.Trisasongko, K. Gandasasmita, dan R. Kusumo. 2011. Pemetaan potensi konversi lahan sawah dalam kaitan lahan pertanian berkelanjutan dengan analisis spasial. Dalam D.P. Ariyanto, WS Dewi, dan Suwardi (Penyunting). Prosiding Seminar dan Kongres HITI X, di Solo. Hal. 554-561.

Christina, D. 2011. Identifikasi Lahan potensial untuk mendukung usulan perencanaan lahan pertanian pangan berkelanjutan: studi kasus di Provinsi Jawa Barat [Tesis]. IPB. Bogor.

Departemen Pertanian. 2006. Naskah Akademik Pengelolaan Lahan Pertanian Abadi. Departemen Pertanian Republik Indonesia. Jakarta.

Hardjowigeno, S. dan Widiatmaka. 2007. Evaluasi Kesesuaian Lahan dan Perencanaan Tata Guna Lahan. Gajah Mada University Press. Yogyakarta.

Jankowski, P. 1995. Integrating GIS and Multiple Criteria Decision Making Methods. International Journal of Geographical Information System. 9: 251-273. http://informaworld.com/terms-and-conditions-ofacess.pdf [3 Mei 2011]

Kasumbogo, U. 2010. Penerapan Pertanian Berkelanjutan Untuk Meningkatkan Ketahanan Pangan. Jakarta.

Lanya, I. dan N.N. Subadiyasa. 2011. Klasifikasi dan pemetaan kawasan lahan pertanian pangan berkelanjutan berbasis Remote Sensing dan GIS (Kab Tabanan Sebagai Model). Dalam D.P. Ariyanto, W.S. Dewi, dan Suwardi (Penyunting). Prosiding Seminar dan Kongres HITI X, di Solo. Hal. $535-541$.

Saaty, T.L. 1993. Pengambilan Keputusan Bagi Para Pemimpin: Proses Hirarki Analitik untuk Pengambilan Keputusan dalam Situasi yang Kompleks. Setiono (penerjemah); Peniwati (editor). Pustaka Binaman Pressindo. Jakarta.

Sawit Watch. 2010. Mewujudkan keadilan Ekologis bersama Masyarakat Adat/Lokal, Pekebun Sawit dan Buruh Sawit. Bogor.

Sekretaris Kabinet. 2009. Undang-Undang Nomor 41 Tahun 2009 tentang Perlindungan Lahan Pertanian Berkelanjutan. 